\title{
"Talk about Chemistry": A Voluntary and Effective Integration among the Players of Teaching Chemistry
}

\author{
By Adriana Vitorino Rossi ${ }^{*}$
}

The "Talk about Chemistry" (TAC) reported here proposes an integrating action involving undergraduates, new and senior chemistry teachers and teacher educators. It is a 6h annual voluntary meeting to talk about current and stimulating chemistry topics and discuss how to teach and learn them. Short speeches are clear and accessible, in order to encourage the audience's participation. There is no passive role and all people involved express opinions, share experiences and act as educators as they discuss scientific and educational knowledge, teaching practice and professional qualification. These activities provide simultaneously initial training and the continuous education of chemistry teachers. The assessment of this proposal involved spontaneous oral statements and written reports, with positive remarks highlighting the importance of TAC, for teachers to share experiences, expectations, doubts and possible solutions. TAC requires very little resources and prior organization, but has a positive impact regarding the training of chemistry teachers.

Keywords: cooperative learning, teacher education, teacher training

\section{Why Go in this Direction? Reasons for this Work}

Efforts to encourage the training of new teachers who are properly able to teach in Brazilian public schools require the collaboration of many specialized higher school educators and instructors, although the participation of experienced senior public school teachers is of fundamental importance due to the rich and poignant experiences they bring with them. The synergistic interaction between members of these different educational spheres creates a productive and enjoyable workspace for the improvement of all people involved: undergraduate teachers-in-training, senior teachers and teacher educators $^{1}$. Throughout the "Talk about Chemistry" (TAC), these spheres willingly merge into one another, due to a proactive interaction between the members, resulting in direct benefits for the whole group. Besides the personal and collective benefits, however, there are also long-term useful outcomes for the Brazilian society as the individual growth of each public school teacher positively affects the country's education. TAC also provides opportunities of

\footnotetext{
${ }^{*}$ Professor, University of Campinas, Brazil.

${ }^{1}$ Teacher educators are here identified as those teachers in higher schools who are formally involved in pre-service and in- service teacher education.
} 
professional upgrading to senior teachers and reinforcement to the new teachers. Details of the past editions of TAC are available in Portuguese at http://pibidunicamp.wordpress.com/.

The Brazilian basic education system includes elementary school (9 years) and high school (3 years). After high school, students may go to a university firstly as undergraduates (4 to 6 years courses) and then as graduates (masters and doctorate, 2 and 4 years respectively). Students' first contact with chemistry concepts occurs during elementary school science classes, but only become a formal subject in high school. Undergraduate chemistry majors may choose between two possible degrees: a Bachelor of Chemistry degree or a Bachelor of Chemistry Teaching degree (in Portuguese: Licenciatura em Química). This last one is mandatory in order to teach chemistry at a public and/or private Brazilian school and usually takes 4 to 5 years to get it, with no distinct special training regarding public or private schools. At some universities, the undergraduates can get it almost simultaneously with the Bachelor of Chemistry degree (4 years). Despite this possibility, the lack of professional encouragement - such as poor working conditions, low income and little prospects for career growth - discourage students to choose to become a teacher. As a consequence, there is a shortage of chemistry, physics and mathematics teachers, especially at the Brazilian public schools.

Considering the needs of the Brazilian public schools and universities, the opportunity for active dialogue among all the educational agents provides an environment where previous actions may be evaluated, problems can be systematically approached, and new strategies of action are fostered. In this context, the TAC helps to improve both the public school and university agents who interact during these volunteer meetings.

The positive professional development that naturally emerges from this interaction validates the efforts to implement the TAC, which can be viewed as a collective space ${ }^{1}$ of continuous education.

\section{Given What We Want, We Prioritize Actions to Achieve our Objectives}

Theoretical knowledge and guided practical exercises are needed to develop the skills and competencies of a future teacher. In order to fine-tune these training activities, however, the contribution of a senior teacher's professional experience is essential. A senior teacher's contribution is also essential in order to help articulate new perspectives of the current chemical knowledge in order to organize a relevant didactic material, appropriately developed according to each educational level. Having made these considerations, we organize and carry out teaching practices that are collectively developed by both teachers-in-training and senior teachers, whose participation can be leveraged by their continuous education training, under the

\footnotetext{
${ }^{1}$ In this article, we will consider a "collective space" as a space consisting of several people who have common goals and share experiences and activities aimed at achieving these goals. (Mariano, 2014, p. 13)
} 
coordination of a university teacher. This university teacher, in turn, may use these moments of collectivity to help deepen our understanding of Brazil's educational problems. Together, basic school teachers, university teachers and the undergraduate teachers-in-training can reflect and discuss the teaching practices in the light of their experiences and problems encountered in their everyday school life. This reflection should help them choose and develop their pedagogical strategies, as Elliot $(1991,2000)$ pointed out regarding the "researcher teacher". This interaction helps change all the agents involved, immensely contributing to the formation of new chemistry teachers and improving the training and the performance of senior teachers and teacher educators.

\section{Context in which the Work Is Inserted}

Educating new chemistry teachers is a primary mission in the Brazilian scenario of a deep deficit of teachers, especially in this area. Several official documents indicate the severity of this lasting situation, as pointed out by Ruiz, Ramos, and Hingel (2007) and a Brazilian governmental court of auditors' report (Tribunal de Contas da União, 2014). In this context, the initiatives for professional qualification and encouragement of the teaching career are indispensable (Rossi, 2013), especially considering the existence of several factors that complicate a teacher's work, which will sooner or later bring serious consequences to society. The students' lack of interest in becoming a chemistry teacher not only reflects these complicating factors, but also expands and intensifies the problem's dimensions - a lack of qualified chemistry teachers will necessarily lead to a lack of interest in the chemical profession. Therefore, in the long-term, we can infer that the number of professionals dealing with chemistry will be reduced. This reduction will cause great impact on Brazil's economic development, especially considering the pre-salt exploration, the use of biomass and the production of legal drugs.

In this scenario, one of the significant governmental programs that seek to stimulate undergraduates seeking a teacher's degree is a Brazilian Federal Program of scholarships called PIBID. PIBID's main goal is to stimulate undergraduates, of all areas of knowledge, to become teachers by taking them to the Brazilian public schools where they will perform activities under a senior teacher's supervision. This senior teacher will work alongside a teacher educator (faculty member), who in turn will be responsible for coordinating the activities. The PIBID stands out for its versatility. The University of Campinas has had a PIBID institutional project since 2010; at the Institute of Chemistry, we developed the subproject for the Bachelor of Chemistry Teaching degree. Since its start, our subproject has involved more than thirty undergraduates and six senior chemistry teachers who act as supervisors of the undergraduates in the activities at six public schools in Campinas, including a center for adult education, named CEEJA.

In our earlier paper (Rossi, 2013) we detailed all the actions that have been 
developed. In this paper, we highlight the TAC as the climax of the desired interactions among our team, which generated interest in the chemistry teacher's career, including the valuable (generally quite relegated) collaboration of senior teachers and the intense process of initial training of new teachers, which cannot be limited to the actions of official forming agents (the higher education teachers), because the dynamic everyday reality of a school is only truly experienced by the teachers of the basic education.

TAC is a six-hour annual event that, in 2014, consolidated its third edition. The event is organized by the teacher educator, who invites undergraduates and senior teachers to this voluntary meeting at the university. We try to establish a dynamic and democratic environment for discussing the current and potentially interesting chemistry topics, with the purpose to inspire the production of contextualized lessons and new approaches. The undergraduate teachers-intraining, with the support of the coordinator and the supervisor of the PIBID subproject, experience all stages of organizing an instructional material, including choice of the main topic, critical survey of literature, preparation of text and multimedia production, including an oral presentation that takes place in a meeting with the voluntary participation of senior chemistry teachers of several public schools of our city. The senior teachers act as advisors of the undergraduates' production and as an active audience - they are not limited to simply hearing the presentation or only voicing specific doubts - everyone has the right (and uses it) to express their opinion on the relevance of the topic and the feasibility of applying it regarding the school's curriculum, besides, they also share professional background related to the theme from their own classroom experiences and discuss their own teaching practices. The teacher educator expands his/her universe of study and researches synergistically with those who constitute this universe, seeking to enhance his/her working practice and integrate the distinct segments, but intertwined in this universe.

Forming new teachers cannot be a mission restricted to the University alone because of a school's dynamics can only be truly understood when experienced. The undergraduate teachers-in-training must be allowed to experience a school's environment. On the other hand, the constant research involving the school produces important results that should be critically applied, and the isolation of many teachers inside the classrooms prevents them from taking advantage of them. Therefore, by integrating the teachers with the academic environment, a spontaneous process of continuous education can rise and foster teachers to enhance their teaching practices. The teacher educator, on the other hand, needs to know the school in a practical and dynamic sense, which is achieved only with the inclusion in the school environment and with the collaboration of those who dominate this environment - the senior teachers - who have the necessary practical experience to truthfully place the teacher educator before the school issues. 
Figure 1. Representation of the Three Level Interaction of Chemical Knowledge with Educational Goals that Works in TAC

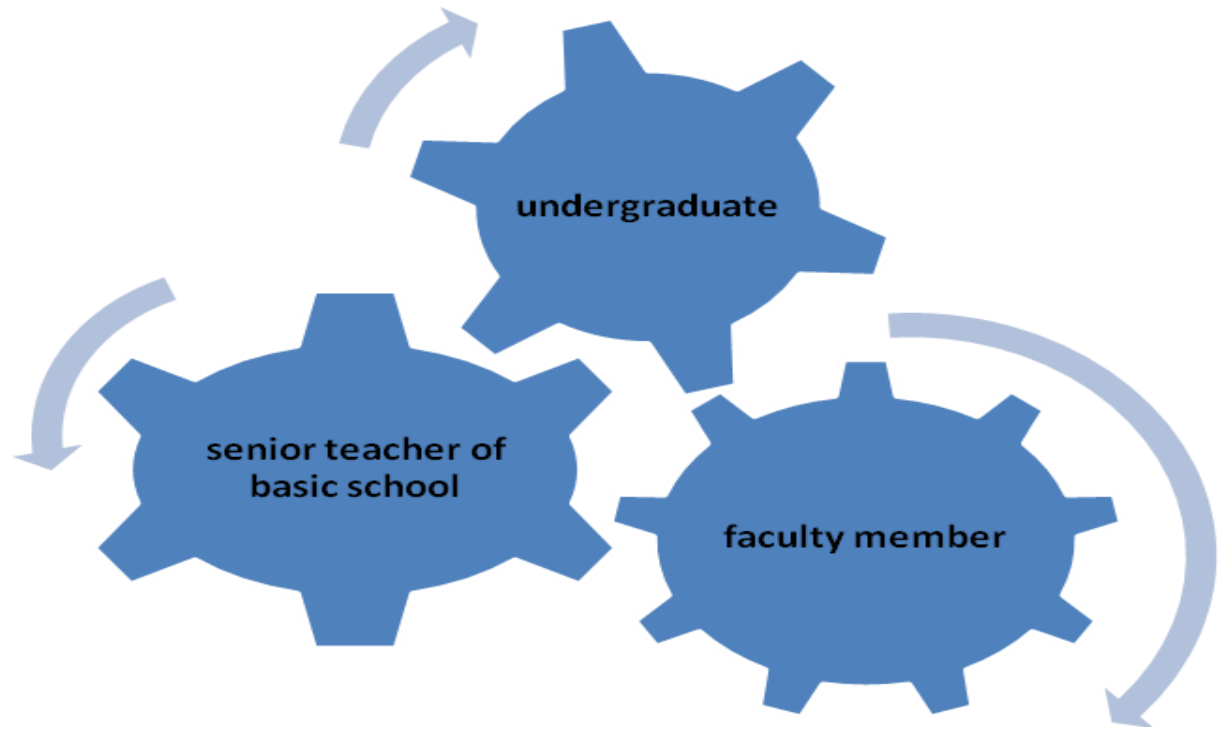

Figure 1 attempt to establish the necessary synergy showing the interaction among the three spheres of integration with the chemical knowledge for educational objectives. To illustrate the developed proposal, the form of each piece of this gear system is modified with every movement, because the interaction between the subjects modifies all of them. The idea of this effective operation of efficient gears adjusted to promote great results is a good analogy to the interaction required, desired and achieved in our TAC, with respect to the initial and continuous education of chemistry teachers. The difference, however, is that in our educational practice, the parts of the gear never remain the same after the movement begins - they constantly change to efficiently keep up the pace.

\section{Current Issues in Chemical Science for Teachers is Innovative?}

When teachers-in-training face the task of producing instructional material, they start to leave the comfort zone of being a student because it is necessary to go into the context of someone who plans to teach. If this production involves themes different from those usually inserted into the regular school curriculum, the challenge is even greater. Whereas teachers are the target audience of this production, the task seems to take herculean proportions. On the other hand, when this challenge is proposed as part of a planned situation, with collectively agreed objectives and cooperatively carried out, the process is productive and less traumatic. The TAC operates in this context. The undergraduates receive additional support from the senior teachers of their future schools. The senior teachers find space to share their experiences, presenting important professional information that deserves to be 
shared, thus breaking the senior teachers' isolation and receiving the due appreciation of their teaching practice. The teacher educator approaches her praxis of the real context of the application, interacts and learns. To this agent, the possibility of working alongside the senior teachers in this guidance process enhances the activity's chances of success and expands the scope of actions that can be performed.

There is no concern regarding specific curriculum content, because we chose to teach a contextualized theme, and inside that theme approach several relevant chemical concepts, of different levels according to the intended purpose. For example, when dealing with the theme "hair", you can introduce concepts of acids and bases, chemical reactions, chemical equilibrium, and organic functions by the discussing the phenomena involved in dyeing or straightening hair. Table 1 summarizes some of the themes that have been discussed, with suggestions of chemical concepts that can be developed.

Table 1.Themes Presented with Concepts Development Suggestions

\begin{tabular}{|l|c|}
\hline Theme & Chemical Concepts \\
\hline Hair & Acid and bases, $\mathrm{pH}$, organic functions, chemical reactions, etc. \\
\hline $\begin{array}{l}\text { Dyes and } \\
\text { Pigments }\end{array}$ & $\begin{array}{c}\text { Organic functions, history of chemistry, organic compounds } \\
\text { reactions, } \mathrm{pH}, \text { etc. }\end{array}$ \\
\hline Nuclear energy & $\begin{array}{c}\text { Subatomic particles, radiochemistry, isotopes, energy of chemical } \\
\text { reactions, environmental chemistry, etc. }\end{array}$ \\
\hline Dead Sea & $\begin{array}{c}\text { Mass and volume relations, solubility, density, concentration units, } \\
\text { etc. }\end{array}$ \\
\hline Sun Blockers & $\begin{array}{c}\text { Concentration units, energy of chemical bonds, energy of chemical } \\
\text { reactions, ultraviolet-visible spectrum, etc. }\end{array}$ \\
\hline $\begin{array}{l}\text { Food, Diets and } \\
\text { Tooth }\end{array}$ & $\begin{array}{c}\text { Chemical functions, chemical representation, organic functions, } \\
\text { solubility, chemical reactions, etc. }\end{array}$ \\
\hline
\end{tabular}

It is not rare to see senior chemistry teachers to complain about the lack of examples of contextualized themes to introduce in high school chemistry classes. In an attempt to minimize this difficulty, the themes addressed in TAC are chosen by considering scientific and technological updates related to chemical concepts that are covered in high schools in order to aid the teachers in developing several levels of approaches in chemistry classes. Every material presented in TAC (texts, presentations, and experiments) is produced by undergraduates and teachers from the PIBID team, and is freely shared at the PIBID team's blog ${ }^{3}$.

The teaching/learning strategies presented by the undergraduate teachersin-training at TAC are planned and executed in collaboration with the coordinator and the supervisor of the PIBID subproject. This is a monitored process that gives full support to solve the doubts and combat the insecurity of exposing oneself in a public presentation. We exercise this support in an organized manner to ensure the necessary autonomy of the teachers-in-training that are thus inserted in a participatory manner in their formative process. The

\footnotetext{
${ }^{3}$ http://pibidunicamp.wordpress.com
} 
following steps are involved:

- search for proper bibliographic material and a selection of references;

- language adequacy (translating chemical knowledge to school level);

- organization of ideas to produce a text and multimedia production, including experimental demonstrations and/or interactive activities;

- oral presentations for teachers and undergraduates.

\section{Innovation with the Contribution of Senior Teachers in Training the Undergraduates}

As in most undergraduate courses, internships with professionals are essential to training the students. In the Brazilian Teacher Education Degree programs, the students must perform 400 hours of internship at schools, alongside senior teachers. Although this interaction's importance has been previously discussed, the undergraduate's experience is limited to only a few teachers from the same school. In the TAC, the teachers-in-training interact with a larger number of teachers from many different schools, which greatly expands the universe of differentiated contributions that are shared to enrich their training in a dynamic and spontaneous process. Although the senior teachers' experiences shared in the internship cannot be neglected, there is not enough space for them to share this valuable knowledge. Creating opportunities for sharing professional experiences is urgent because it is important to support the most qualified education of new teachers. In this context, the TAC is a modest option that emerged in order to improve the initial education of new chemistry teachers, giving voice to the senior teachers whose teaching practice has features that need to be shared.

\section{Reflecting on Successes and Problems of TAC Proposal to Evaluate It}

In 2014, the third edition of TAC was supported by a governmental educational board. It suggests the recognition of the proposal's value. In practice, it means to enable interested teachers to participate voluntarily in the TAC as part of their professional continuous education. It shows us the relevance of the developed proposal, which must be carefully conducted since a diagnostic evaluation is essential to organize the programming and integrate it for the benefit of the education of all people involved. As the TAC was inserted in an official program of activities for chemistry teachers in 2014, there was an assessment process, consisting of written reports with strong and positive aspects, eventual problems to be overcome, and suggestions.

In short, we received 29 evaluation forms, all highlighting positive aspects and in $36 \%$ of them, the teachers requested the inclusion of chemical experiments, especially using household materials. $28 \%$ of the forms, 
expressed interest to maintain or intensify the exchange of experiences, including time for preparing presentations about their own practices, and 32\% of them suggested increasing the number of meetings. These data indicate that the senior teachers expect professional meetings with more active initiatives of participation, which agrees with our objectives, conceiving the TAC also as a proposal for the continuous education of teachers. As Schnetzler (2002), we also believe in going beyond the acquisition of scientific concepts to break the distance from the university proposals and the reality of everyday school life. Some other manifestations involving strong and positive aspects indicate that our main goals of integrating teachers in the cooperative environment of discussion in a collective space have been achieved, as is denoted from some transcribed and translated excerpts:

All experiences exchanged among colleagues always add to our form of working in the classroom; with the reports, I got more knowledge of materials that I can use in the classroom.

The exchange of information among professionals in activity is very important, as we have challenges in common to overcome.

\section{The sharing of classroom experiences allowed me to reflect and thus improve how I teach the students.}

After all, it is important to understand what happened in the teaching/learning process, from the undergraduates' perspective.

It seems strange, but our professional practice indicates that most students who want to become a chemistry teacher do not like to speak in public and insofar they advance in the course, they get more trapped on sophisticated and specific chemical concepts and their language becomes extremely technical to explain general issues involving chemistry to a non-chemist. In this context, the production of the instructional material starting from the choice of the theme and the literature, culminates with the oral presentation of a cooperative production supported by senior teachers to an audience of senior teachers with clear and true objectives of professional improvement represents an outstanding point in the formation of these teachers-in-training.

The positive manifestations of senior teachers that participated of the TAC, regarding the performance of the undergraduates, including aspects related to conceptual correctness, suitability of content and language, are indications that our objectives have been achieved and the students did improve as we intended. In this formative evaluation process, the successful results overthrow the initial resistance, the fear of public speaking and the difficulties of translating scientific knowledge to accessible and correct forms to reach different audiences. The student who made the "hair" themed presentation in 2014, for example, became highly motivated to conduct a thematic workshop for the passer by's at the CEEJA, which was very well received by the public. The positive results prompted the development of a 
work (Oliveira, Zanini, \& Rossi, 2014) which was presented by him in the XVII ENEQ, a Brazilian meeting of chemistry educators and researchers, held from August 19 to $22^{\text {nd }}, 2014$ at the University of Ouro Preto. This was his first attendance to a scientific event and as it resulted from his participation on the $\mathrm{TAC}$, it can be an indicative of our proposals.

Although there are strong indicatives to TAC's success regarding the initial and continuous teacher education, the proposal's success regarding the increase in number of new teachers at schools is still uncertain. Despite the fact that all undergraduates that take part of TAC get their Bachelor of Chemistry Teaching degree, it is impossible to attest that they actually go into teaching. Some of them are still undergraduates concluding the Bacherlor's Degree, some are getting their Masters degree and others start working as chemists since the Chemistry Teaching degree also gives them that possibility. Therefore, the TAC proposal should not be considered as an isolated solution, but as an attempt that must be accompanied by many other projects developed by teacher educators with the firm objective of reducing the teacher shortage in Brazil. For this to be possible, however, more faculty members must choose to act as teacher educators - a scenario very far from the current reality, where many of those who are highlighted in chemistry research still remain a part of the teacher's education non-curricular activities, such as TAC.

\section{Final Thoughts}

A conversation involves talking and listening. If one has ears, let him hear. If one has something to say, let him be heard. A conversation must be a dialogue. Speakers and listeners participate in a dialogue, in a process that catalyzes change. This process is indispensable for the initial and continuous education of teachers at different educational levels. We thus leave here the "Talk about Chemistry" proposal, a simple yet potentially great activity; although we also acknowledge that it will not solve all the problems. We do hope, however, that it may be useful to others.

\section{Acknowledgments}

TAC is a result of the teamwork constituted by undergraduates and teacher supervisors. In addition to the team, the participation of the senior teachers is essential. To all, sincere and heartfelt thanks.

\section{References}

Elliott, J. (1991). Action research for educational change. Philadelphia, CA: Open University Press.

Elliott, J. (2000). La investigación-acción en educación [The action research in 
education]. (4th ed.). Madrid: Ediciones Morata.

Mariano I. A. (2014). Cooperative construction of actions in the school context from discussions of Science with teachers in a collective space (Master's thesis). Retrieved from http://bit.ly/1N13wzA.

Oliveira, V. G., Zanini, S. M. C., \& Rossi. A. V. (2014). Oficina sobre Alimentação: uma ação desenvolvida em um Centro Estadual de Educação de Jovens e Adultos a partir do PIBID [Workshop on food: an action developed into a adult education center from the PIBID]. In G. P. Souza (Ed.) Anais do XVII Encontro Nacional de Ensino de Química (p. 4787). Ouro Preto, MG: UFOP.

Rossi, A. V. (2013). PIBID and Chemistry Teacher degrees in an institutional context of chemical research highlighted: scenario, problems and prospects. Química Nova na Escola, 35, 255-263. Retrieved from http://bit.ly/1JMjvAy.

Ruiz, A. I., Ramos, M. N., \& Hingel, M. (2007, May). Escassez de professores no Ensino Médio: propostas estruturais e emergenciais [Shortage of teachers in high school: emergency and structural proposals]. Retrieved from http://bit.ly/1O8g1xF.

Schnetzler, R. P. (2002). Conceptions and Warnings about Continuous Teacher Education in Chemistry. Química Nova na Escola, 16, 15-20. Retrieved from http://bit.ly/1FsPiVc.

Tribunal de Contas da União (2014, April). Relatório de Auditoria.(Fiscalização ${ }^{\circ}$ 177/2013) [Audit report. (Supervision No. 177/2013)]. Retrieved from http://bit.ly/1 KW3mwA. 